\title{
Mitigation of Voltage Sag by Using Shunt Active Power Filter
}

\author{
Juned Shabbir Shaikh ${ }^{1}$, Javed Yunus Shaikh ${ }^{2}$, Vikar Aavesh Teli ${ }^{3}$, Mohsin Salim Gangat ${ }^{4}$, \\ Syed Irfan Sadulla ${ }^{5}$ \\ ${ }^{1,2,3}$ Assistant Professor, Electrical Engineering Department JIEMS Akkalkuwa \\ ${ }^{4}$ Assistant Professor, Electronics \& Telecommunication Department JIEMS Akkalkuwa \\ ${ }^{5}$ Assistant Professor, Mechanical Engineering Department JIEMS Akkalkuwa
}

\begin{abstract}
Power quality problem is an occurrence manifested as an nonstandard voltage, current or frequency that results in failure of end use equipments .one of the major problem in power quality is voltage sag .To improve the power quality, custom power devices are used. The custom power device used here is SAPF(Shunt active power filter) is role to compensate load voltage during the different fault conditions like voltage sag, single line to ground, double line to ground faults .In this work, PI controller and discrete PWM pulse generator are used for the control purpose.
\end{abstract}

Keywords - component, PWM(pulse width modulation) technic, SAP F(shunt active power filter),PI(proportional integral) controller

\section{I -INTRODUCTION}

$\mathrm{T}_{\mathrm{h}}$ he IEEE standards defines power quality as "the concept of powering and grounding sensitive electronic equipment in a manner that is suitable to the operation of that equipment" .Power quality may also be defined as "the measure, analysis, and improvement of bus voltage ,usually a load bus voltage, to maintain that voltage to be a sinusoidal at rated voltage and frequency".

The electric power system is considered to be composed of three functional b lo c k s -generation, transmission and distribution, The distribution systems must deliver electric power to each customer's premises from bulk power systems. Distribution system locates the end of power system and is connected to the customer directly ,so the power quality mainly depends on distribution system .In the earlier days , the major focus for the power system reliability was on generation and transmission only as these more capital cost is involved in these.

Initially for the improvement of power quality or reliability of the system FACTS devices like static synchronous compensator (STATCOM) ,static asynchronous series compensator (SSSC) ,interline power flow controller (IPFC), and unified power flow controller (UPFC) etc are introduced.These FACTS devices are designed for the transmission system .But now a days, more attention is on the distribution system for the improvement of power quality, these devices are modified and known as custom power devices. 


\section{International Journal of Innovations in Engineering and Science, www.ijies.net}

The main custom power devices which are used in distribution system for power quality improvement are distribution static synchronous compensator (DSTATCOM), shunt active power filter (SAPF) , active power filter (AF), unified power quality conditioner (UPQC) etc .Here we use the custom power device is SAPF which gives $50 \%$ improvement in mitigation of voltage sag than the other devices. The shunt active power filter is used with PI controller for the power quality improvement in the distribution system.

\section{II -POWER QUALITY}

Both electric utilizes and end users of electric power are becoming increasingly concerned about the quality of electric power. The term power quality has become one of the most prolific buzzwords in the power industry since the late 1980s.It is an umbrella concept for a multitude of individual types of power system disturbances the issues that fall under this umbrella are not necessarily new. What is new is that engineers are now attempting to deal with these issues using a system approach rather than handling them as individual problem.

The power quality has serious economic implications for customers, utilities and electrical equipment manufacturer .Large number industries involves increasing use of computers, microprocessors and power electronic system such as adjustable speed drives .The power electronic systems also contribute to power quality problems(generating harmonics). The impact of power quality problems is increasingly felt by customers -industrial ,commercial and even residential.

\section{III-PROBLEMS ASSOCIATED WITH POWER QUALITY}

a) Transients

A transient is that a part of change in a system variable that disappears during transition from one steady state operation to another. Transient can be classified into two categories -impulsive transients and oscillatory transients.An impulsive transient is a sudden, non power frequency change in voltage, current etc that it is unipolar in nature . The polarity of such a transient can be either positive or negative. An oscillatory transient is a sudden, non power frequency change in the steadystate condition of voltage, current, or both that includes both positive and negative polarity values.

\section{b) Long Duration Voltage Variations}

When RMS (root mean square) deviations at power frequency last longer than one minute, then we say they are long duration voltage variations. They can be either over voltages which is greater than 1.1p.u or under a voltage which is less than 0.9 p.u.Over voltage is due to switching off a load or energizing a capacitor bank. Also incorrect tap settings on transformers can result in over voltages

.under voltage are the results of actions which arethe reverse of events that cause over voltages i.e. switching in a load or switching off a capacitor bank.

\section{c) Sustained Interruptions}

If the supply voltage becomes zero for a period of time which is greater than one minute, then we say that it is a sustained interruption. Normally, voltage interruption lasting for more than one minute is often unending and requires humanintervention to restore the supply.

\section{d) Short Duration Voltage Variations}

The short duration voltage variations are generally caused by fault conditions like single line to ground and starting of large loads such as induction motors .The voltage variations can be temporary voltage dips i.e. sag or temporary voltage rise i.e. swells or a absolute loss of voltage which is known as interruptions.

\section{i) Voltage sags}

Voltage sag is defined as the reduction of rms voltage to a value between 0.1 and 0.9p.u and lasting for duration between 0.5 cycle to 1 minute. Voltage sags are mostly caused by system faults and last for durations from 3 cycles to 30 cycles depending on the fault clearing time. It is to be noted that under-voltages (lasting over a minute) canbe handled by voltage regulation equipment. An interruption occurs when the supply voltage or current decreases to less than 0.1 p.u for a period of time not exceeding 1 minute .Interruptions can be the result of power system faults, equipment failures, and control malfunctions.

\section{IV -SOLUTION OF POWER QUALITY PROBLEMS}

For the improvement of power quality there are two approaches. According to first approach the solution to the power quality problems can be done from the utility side. The first approach is called load conditioning, which ensures that the equipment is less sensitive to power disturbances, allowing the operation even under 


\section{International Journal of Innovations in Engineering and Science, www.ijies.net}

significant voltage distortion. The other solution is to install line conditioning systems that suppress the power system disturbances. In this approach the compensation device is connect to low and medium voltage absorbing independently controllable real and reactive power at its ac output terminal. Like in a DSTATCOM, the SAPF is made of a solid-state dc to ac switching power converter that injected a set of three-phase ac output voltages in series and synchronism with the distribution feeder voltages.

The amplitude and phase angle of the injected voltages are variable thereby allowing control of the real and reactive power exchange between the SAPF and the distribution system.

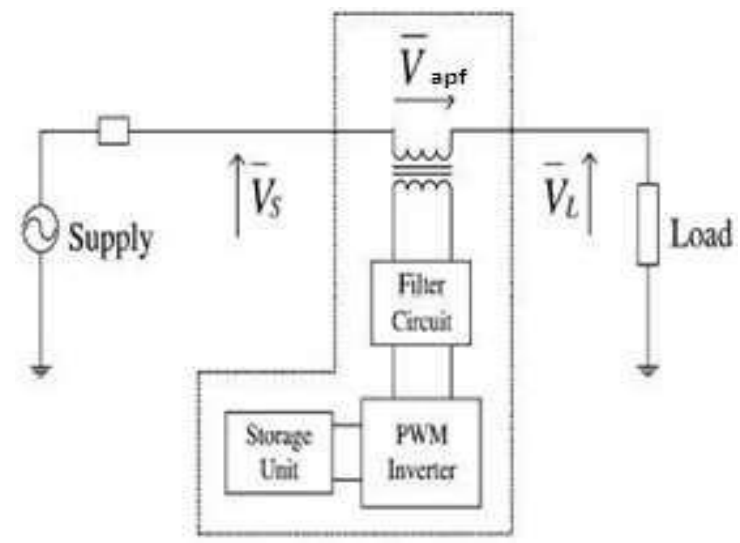

Fig1-Schematic diagram of Shunt activepower filter

The dc input terminal of a SAPF is connected to an energy source or an energy storage device of appropriate capacity. The reactive power exchanged between the SAPF and the distribution system is internally generated by the SAPF without ac passive reactive components. The real power exchanged at the SAPF output ac terminal is provided by the SAPF input dc terminal by an external energy source or energy storage system.

\section{BASIC ARRANGEMENT OF SAPF}

The SAPF mainly consist of the following components:

1. An injection transformer

2. DC charging unit

3. Storage Devices

4. A voltage source Inverter(VSI)

5. Harmonic filter

6. A Control and protection system .

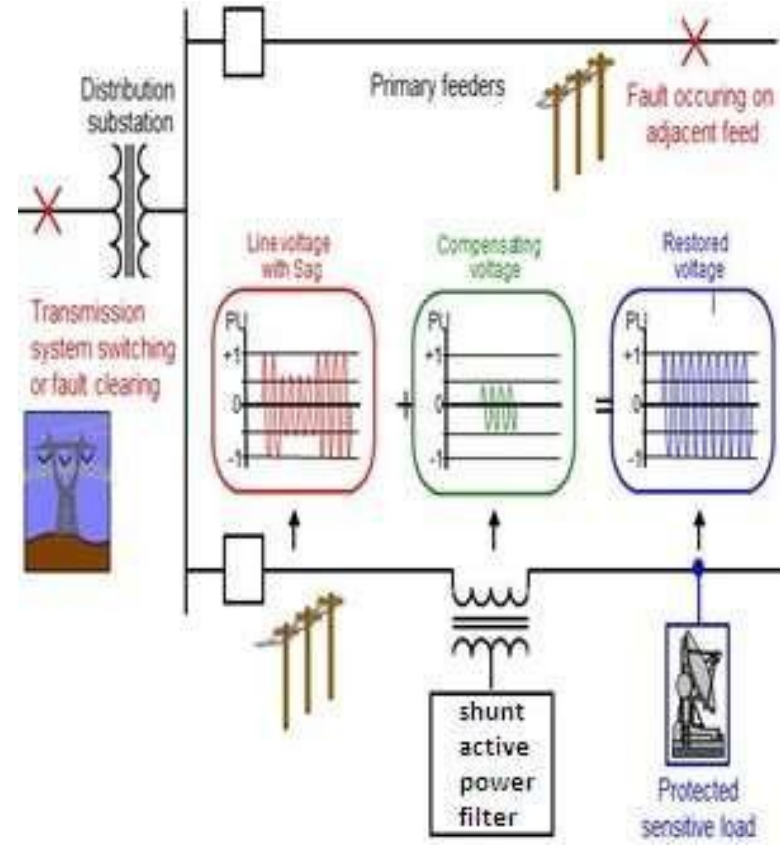

Fig2-Working principles of SAPF

\section{INJECTION TRANSFORMER}

Three single phase transformers are connected in series with the distribution feeder to couple the VSI (at the lower voltage level) at the higher distribution voltage level. It links the SAPF system to the distribution network via the $\mathrm{HV}$-windings and transforms and couples the injected compensating voltages generated by the voltage source converters to the incoming supply voltage.

\section{CHARGING UNIT}

The dc charging circuit is used after sag compensation event the energy source is charged again through $\mathrm{dc}$ charging unit. It is also used to maintain dc link voltage at the nominal dc link voltage.

\section{VOLTAGE SOURCE INVERTER}

A VSI is a power electronic system consists of a storage device and switching devices, which can generate a sinusoidal voltage at any required frequency, magnitude, and phase angle. It could be a 3 phase -3 wire VSI or 3 phase - 4 wire VSI. Either a conventional two level inverter or a three level inverter is used. For SAPF application, the VSI is used to momentarily replace the supply voltage or to generate the part of the supply voltage which is absent. The function of storage devices is to supply the required energy to the VSI via a dc link for the generation of injected voltages. Here the energy storage devices are capacitor. 


\section{International Journal of Innovations in Engineering and Science, www.ijies.net}

\section{HARMONIC FILTER}

As SAPF consist of power electronic devices, the possibility of generation self harmonics is there so harmonic filter is also become a part of SAPF. The main task of harmonic filter is to keep the harmonic voltage content generated by the VSI to the acceptable level.

\section{CONTROL AND PROTECTION}

A controller is also used for the proper operation of the SAPF system. Load voltage is sensed and passed through a sequence analyzer. The magnitude of load voltage is compared with reference voltage. Pulse width modulated (PWM) control technique is applied for inverter switching so as to generate a three phase $50 \mathrm{~Hz}$ sinusoidal voltage at the load terminals. Chopping frequency is set aside in the range of a few KHz.PI controller is used with the IGBT inverter to maintain 1p.u. voltage at the load terminals. The controller input is an actuating signal which is the difference between the Vref(reference voltage) and Vin(actual voltage). An advantage of a proportional plus integral controller is that its integral term causes the steady-state error to be zero for a step input.Output from the controller block is in the form of an angle that is used to establish an additional phase-lag/lead in the three-phase voltages. All protective functions of the SAPF should be implemented in the software.

\section{V- OPERATING MODES OF SAPF}

The SAPF is designed to inject a dynamically controlled voltage i.e. VSAPF, which is generated by a forced commutated converter. This voltage is injected in series to the bus voltage by means of an injection transformer. The momentary amplitudes of the three injected phase voltages are controlled such as to remove any harmful effects of a bus fault to theload voltage VL. This means that any differential voltages caused by transient disturbances in the ac feeder will be compensated by a equivalent voltage generated by the converter and injected on the medium voltage level through the injection transformer. The SAPF has three modes of operation which are: protection mode, standby mode, injection/boost. In protection mode, if the current on the load side exceeds a tolerable limit due to any fault or short circuit on the load, SAPF will isolate from the system. In standby mode the voltage winding of the injection transformer is short circuited through converter. In the Injection/boost mode the SAPF is injecting a compensating voltage through the injection transformer due to the detection of a disturbance in the supply voltage.

\section{VI-ADVANTAGE OF PROPOSED SYSTEM}

The DC Link capacitor is eliminated .The size, volume and cost of the SAPF are low. Energy storage is possible even during fault occurrence. It can compensate the unbalance voltage sags and swells. It will give a guarantee that the regulated voltage can be achieved for sensitive loads.

\section{VII- APPLICATION}

Practically, the capability of injection voltage by SAPF system is $50 \%$ of nominal voltage. This allows SAPFs to successfully provide protection against sags to $50 \%$ for durations of up to 0.1 seconds. Furthermore, most voltage sags rarely reach less than $50 \%$.

\section{VIII -SIMULINK RESULTS}

In this model a single line to ground fault has the fault resistance is $0.001 \mathrm{ohms}$ and the ground resistance is $0.001 \mathrm{ohms}$.The fault time is 0.3 to $0.5 \mathrm{~s}$. The result of the load voltage is given

Simulink Model For Fault Simulation Model For Fault With Single Phase Ground Fault Condition

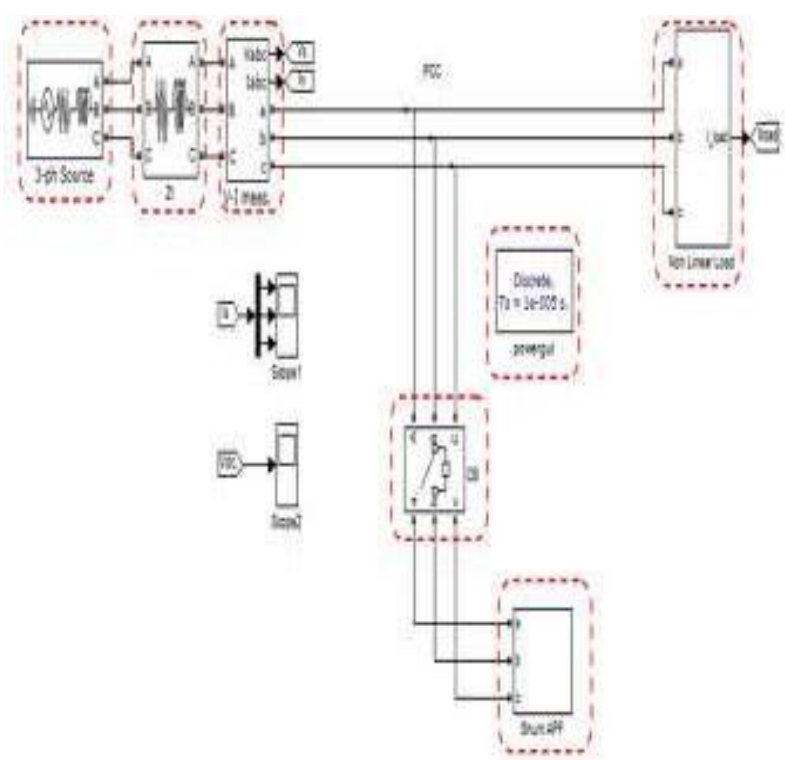

Fig 3: Simulink Model 


\section{International Journal of Innovations in Engineering and Science, www.ijies.net}

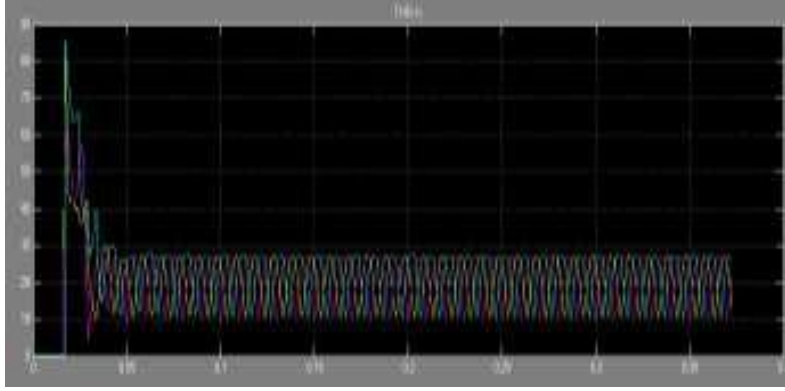

Fig 4-Graph of Source current in presence of apf

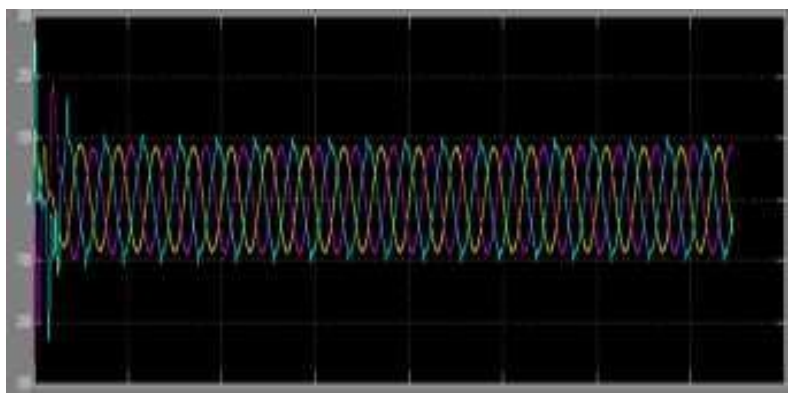

Fig5. Graph of THD in presence of apf

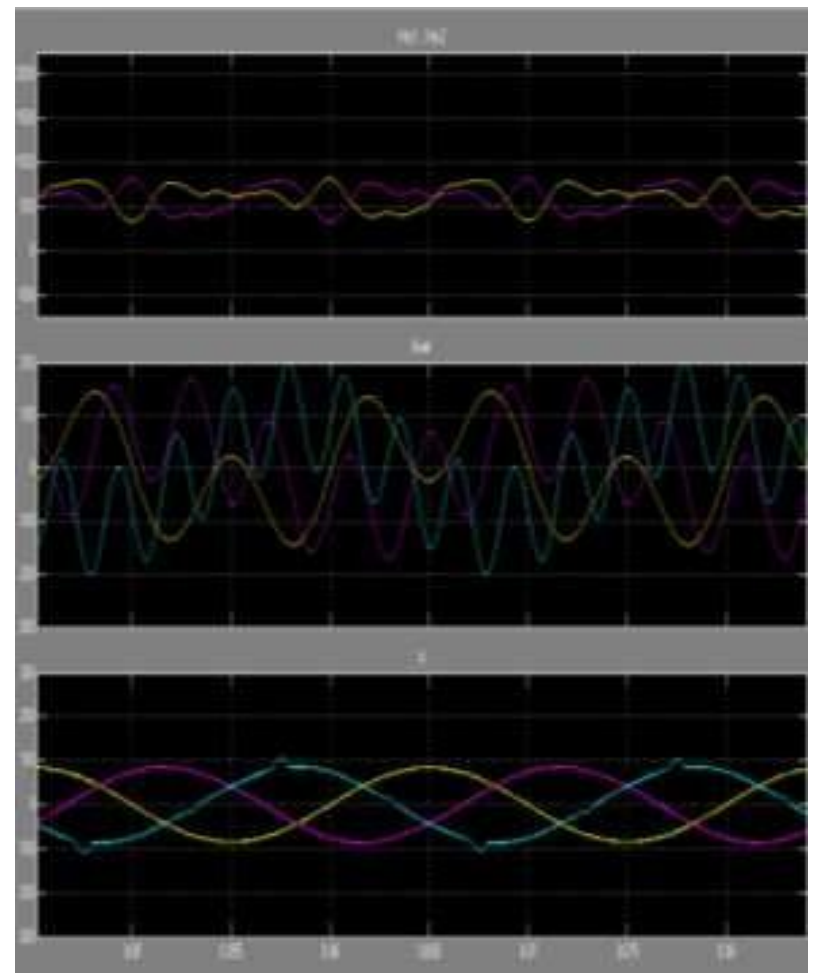

Fig.6 - Graph showing the operation of PI controller

\section{CONCLUSION}

In this Paper, Shunt active power filter is proposed for eliminating the problem of voltage dip, swell and other voltage disturbances problem in industrial distribution system using SAPF .The feed foreword technique is proposed in this paper. The simulation result shows the fault clearing using SAPF. From the whole it is clear from the result that, while increase in load in case of induction motor, the THD and unbalance load voltage aredecreased by using SAPF.

\section{ACKNOWLEDGEMENTS}

The authors are thankful to president JIIU's G. M. Vastanvi and Dr. Kamaluddin Syed, Principal, JIEMS Akkalkuwa for their encouragement and support.

\section{REFERENCES}

[1] Yash Pal, A. Swarup Senior Member, IEEE, and Bhim Singh, Senior Member IEEE"A Review of Compensating. Distribution Conference and Exposition, IEEE PES, vol.3,pp.931-936,2009.

[2] D. Daniel Sabin, Senior member IEEE , and Ambra Sannino, IEEE "A summary of the draft IEEE P1409 Custom Power Application Guide" Transmission and Michael D. Stump, Gerald J. Keane "The Role, of Custom Power Products in Enhancing Power Quality at Industrial Facilities", Energy Management and Power Delivery.vol. 2,507517,International Conference 2013.

[3] Bingsen Wang, Giri Venkataramanan and Mahes Illindala," Operation and Control of a Shunt active power filter Using Transformer Coupled H-Bridge Converters", IEEE Transactions on power electronics, vol.21,pp.1053-1061,july 2012.

[4] Fawzi AL Joeder" Modelling and Simulation of Different System Topologies for Shunt active power filter" Electric Power and Energy Conversion Systems,EPECS'09.InternationalConferences, IEEE, pp.1-6,2009.

[5] D.N.Katole Research Scholor :Department of Electrical Engg. G. H.Raisoni College of Engineering Nagpur, Maharashtra India."Analysis and Mitigation of Balanced Voltage Sag with The Help of Energy Storage System" ICETET pp.317$321,2010$.

[6] H.P.Tiwari and Sunil Kumar Gupta "Shunt active power filter against Voltage Sag" International Journal Of Innovation, Management and Technology.vol. 1,no. 3,pp.232-237,2010.

[7] L. Moran, L. Dixon, and R. Wallace, "A three-phase active power filter operating with fixed switching 
Vol. 6 , No. 10, 2021, PP. 226-231

International Journal of Innovations in Engineering and Science, www.ijies.net

frequency for reactive power and current harmonic compensation," Industrial Electronics, IEEE Transactionson, vol. 42, no. 4, pp. 402-408, 2011.

[8] B. Singh, K. Al-Haddad, and A. Chandra, "A review of active filters for power quality improvement," Industrial Electronics, IEEE Transactions on, vol. 46, no. 5, pp. 960-971, 2012.

[9] H. Akagi, E. Watanabe, and M. Aredes, Shunt Active Filters. Wiley-IEEE Press, 2007, pp. 109 - 220. 